variant predominance, South Korea. Emerg Infect Dis. 2022 Feb [cited 2021 Dec 22]. https://wwwnc.cdc.gov/eid/ article/28/2/21-1774_article

5. Ali ST, Wang L, Lau EHY, Xu XK, Du Z, Wu Y, et al. Serial interval of SARS-CoV-2 was shortened over time by nonpharmaceutical interventions. Science. 2020;369:1106-9. https://doi.org/10.1126/science.abc9004

6. Madewell ZJ, Yang Y, Longini IM Jr, Halloran ME, Dean NE. Household transmission of SARS-CoV-2: a systematic review and meta-analysis. JAMA Netw Open. 2020;3:e2031756. https:/ / doi.org/10.1001/jamanetworkopen.2020.31756

7. European Centre for Disease Prevention and Control. Assessment of the future emergence and potential impact of the SARS-CoV-2 Omicron variant of concern in the context of ongoing transmission of the Delta variant of concern in the EU/EEA, 18th update [cited 2021 Dec 23].

https:/ / www.ecdc.europa.eu/en/publications-data/ covid-19-assessment-further-emergence-omicron-18th-riskassessment

8. UK Health Security Agency. SARS-CoV-2 variants of concern and variants under investigation in England: technical briefing 32 [cited 2021 Dec 22]. https:/ / assets.publishing. service.gov.uk/government/uploads/system/uploads/ attachment_data/file/1042688/RA_Technical_Briefing_32_ DRAFT_17_December_2021_2021_12_17.pdf

Address for correspondence: Young-Joon Park, Director of Epidemiologic Investigation, Korea Disease Control and Prevention Agency, 187 Osongsaengmyeong2-ro, Osong-eup, Heungdeok-gu, Cheongju-si, Chungcheongbuk-do 28159, South Korea; email: pahmun@korea.kr

\section{Restaurant-Based Measures to Control Community Transmission of COVID-19, Hong Kong}

\author{
Faith Ho, Tim K. Tsang, Huizhi Gao, Jingyi Xiao, \\ Eric H.Y. Lau, Jessica Y. Wong, Peng Wu, \\ Gabriel M. Leung, Benjamin J. Cowling
}

\begin{abstract}
Author affiliations: World Health Organization Collaborating Centre for Infectious Disease Epidemiology and Control, University of Hong Kong, Hong Kong, China (F. Ho, T.K. Tsang, H. Gao, J. Xiao, E.H.Y. Lau, J.Y. Wong, P. Wu, G.M. Leung, B.J. Cowling); Hong Kong Science and Technology Park, Hong Kong (E.H.Y. Lau, P. Wu, G.M. Leung, B.J. Cowling)
\end{abstract}

DOI: https://doi.org/10.3201/eid2803.211015
Controlling transmission in restaurants is an important component of public health and social measures for coronavirus disease. We examined the effects of restaurant measures in Hong Kong. Our findings indicate that shortening operating hours did not have an effect on time-varying effective reproduction number when capacity was already reduced.

A s of April 14, 2021, a total of 11,608 cases and 207 deaths from coronavirus disease (COVID-19) had been reported in Hong Kong (1). A series of community epidemics have occurred, the largest of which have been the third wave in June-October 2020, which had 3,978 cases, and the fourth wave in November 2020-March 2021, which had 6,048 cases. To suppress local transmission of COVID-19, the government implemented a combination of public health and social measures (PHSMs): bar closures, restaurant capacity restrictions and opening hour restrictions, bans on live music performances and dancing, and work-from-home advisories (2). Ongoing assessment of the effect of these measures on transmission can guide evidence-based policy. One type of location in which COVID-19 transmission is known to occur is restaurants (3). Earlier studies have evaluated the impact of PHSMs, including restrictions on large group gatherings (4-6), but the specific effect of restaurant measures was not studied. Here we focus on the effect of restaurant measures on transmission in Hong Kong.

We collected details and time of implementation of each intervention of all the PHSMs applied during the third and fourth waves from the official reports of the Hong Kong government (7) (Appendix Table 1, https:/ / wwwnc.cdc.gov/EID/ article/28/3/21-1015-App1.pdf). In wave 3, a ban on dine-in service after 6:00 PM was in force during July 15-August 27, 2020 (Figure, panel A). Other PHSMs were implemented on the same day and kept in place for longer. Wave 4 was initiated by multiple superspreading events in a network of dancing venues. A ban on dine-in service after 6:00 PM was implemented on December 10, 2020, which was a week to a month later than the implementation of other PHSMs (Figure, panel B). Hence, we could disentangle the effect of shortened dine-in hours from other measures. No other PHSMs were implemented before the study period.

To determine the effect of the ban on dine-in services after 6:00 PM, we applied a previous approach to estimate time-varying reproduction number $\left(\mathrm{R}_{\mathrm{t}}\right)$ $(8,9)$. Then, we fitted LASSO regression models to 

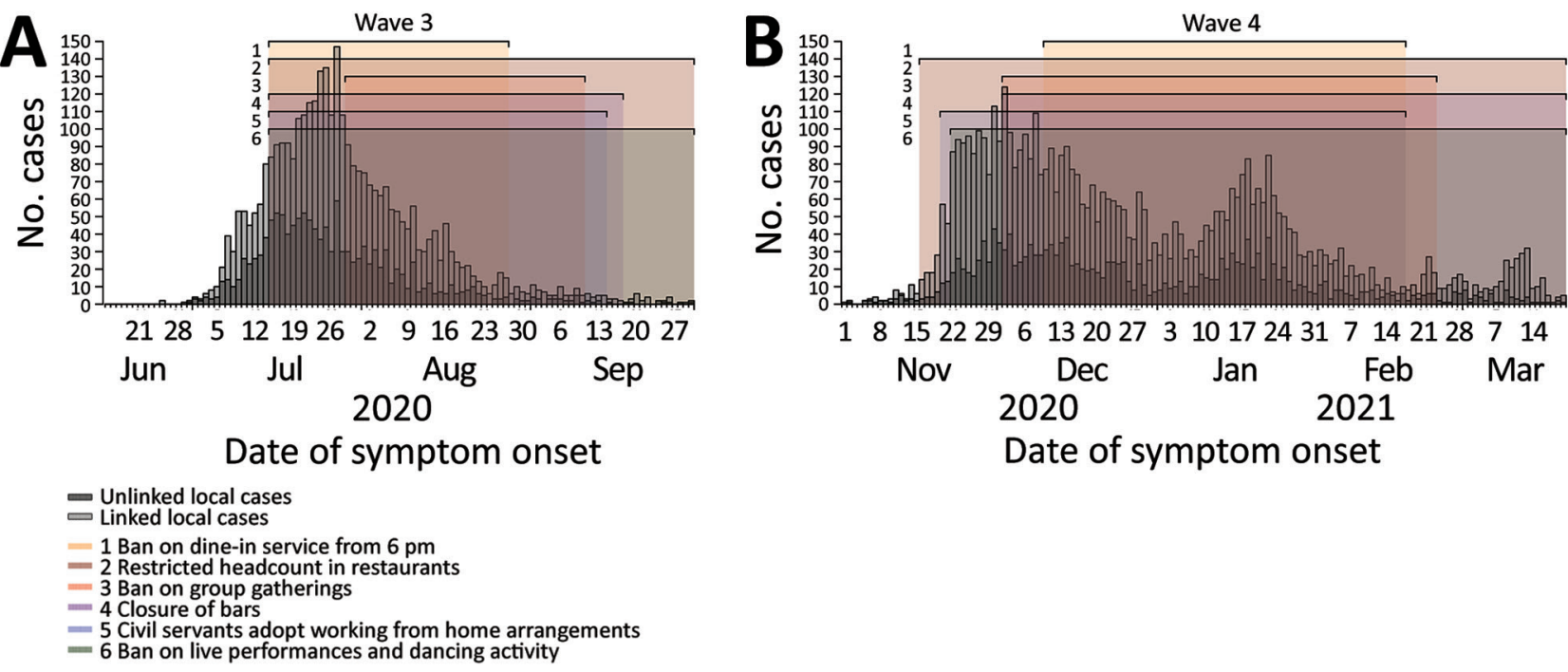

Figure. Use of public health and social measures (PHSMs) to reduce transmission of coronavirus disease in 2 waves of the epidemic, Hong Kong, 2020-2021. A) Incidence and implementation of PHSMs during wave 3, June 15-September 30, 2020. B) Incidence and implementation of PHSMs during wave 4, November 1, 2020-March 20, 2021. Dark and light gray bars represent the incidence of unlinked local cases and linked local cases of coronavirus disease in Hong Kong. Linked local cases are cases that are linked initially or after epidemiological investigation. Effective periods of PHSMs related to restaurants are shown in shaded areas in different colors.

$\log \left(R_{t}\right)$ to assess the effect of the ban on dine-in services after 6:00 PM on $R_{t^{\prime}}$ accounting for the effect from other PHSMs (10). We allowed for a 7-day lag between implementation of a measure and its effect on incidence, to account for the incubation period. In both waves, we grouped the PHSMs other than ban on dine-in services after 6:00 PM into a single variable

Table. Effect on time-varying reproduction number of public health and social measures in waves 3 and 4 of COVID-19, Hong Kong, 2020-2021

\begin{tabular}{|c|c|}
\hline PHSM & $\begin{array}{l}\text { \% Change in } \mathrm{R}_{\mathrm{t}} \\
(95 \% \mathrm{Cl})\end{array}$ \\
\hline \multicolumn{2}{|l|}{ Model 1} \\
\hline \multicolumn{2}{|l|}{ Wave 3} \\
\hline Ban on dine-in service after 6:00 PM† & \\
\hline$\geq 3$ other PHSMs $\ddagger$ & $-53(-59$ to -44$)$ \\
\hline \multicolumn{2}{|l|}{ Wave 4} \\
\hline Ban on dine-in service after 6:00 PM & \\
\hline$\geq 3$ other PHSMs & $-40(-47$ to -28$)$ \\
\hline \multicolumn{2}{|l|}{ Model 2} \\
\hline \multicolumn{2}{|l|}{ Wave 3} \\
\hline Ban on dine-in service after 6:00 PM & 0 \\
\hline $\begin{array}{l}\geq 3 \text { other PHSMs, excluding basic civil } \\
\text { service arrangement }\end{array}$ & $-51(-57$ to -43$)$ \\
\hline \multicolumn{2}{|l|}{ Wave 4} \\
\hline Ban on dine-in service after 6:00 PM & 0 \\
\hline $\begin{array}{l}\geq 3 \text { other PHSMs, excluding basic civil } \\
\text { service arrangement }\end{array}$ & $-38(-46$ to -27$)$ \\
\hline \multicolumn{2}{|c|}{$\begin{array}{l}\text { *Wave } 3 \text { was June 15-September } 30,2020 \text {; wave } 4 \text { was November } 1 \text {, } \\
2020-\text { March } 15,2021 \text {. COVID-19, coronavirus disease; PHSM, public } \\
\text { health and social measure; } R_{t} \text {, reproduction number. } \\
\text { †Because of variable selection and regularization in LASSO regression, } \\
\text { the regression coefficient was shrunk to } 0 \text { in the model. } \\
\text { fOther PHSMs include restricted headcount in restaurants, ban on group } \\
\text { gatherings, bar closure, flexible civil service arrangement, and ban on live } \\
\text { performances and dancing activity. }\end{array}$} \\
\hline
\end{tabular}

to indicate the period when $\geq 3$ of these other PHSMs were in place.

We estimated that the ban on dine-in services after 6:00 PM did not reduce $R_{t}$ in both waves, but other PHSMs were associated with substantial reductions in $R_{t}$. In wave $3, R_{t}$ rose rapidly to 4.5 on June 27 , 2020 , but $\approx 1$ week after measures were applied it was $<1.0$ (Appendix Figure, panel A). Implementation of $\geq 3$ other PHSMs was associated with a 53\% (95\% CI $44 \%-59 \%$ ) decrease in $\mathrm{R}_{\mathrm{t}}$ (Table).

In wave $4, \mathrm{R}_{\mathrm{t}}$ increased to 3.1 on November 16, 2020 , and then decreased to $\approx 1.0$ after PHSMs began (Appendix Figure, panel B). Implementation of $\geq 3$ other PHSMs was associated with a 40\% (95\% CI 28\%$47 \%$ ) decrease in $\mathrm{R}_{\mathrm{t}}$. Another model that excluded basic civil service arrangement in other PHSMs showed that a ban on dine-in service beginning at 6:00 PM did not have an effect (Table). We performed sensitivity analysis to remove the effect of superspreading in wave 3 by changing the start date to July 1, 2020; we found the ban on dine-in service from 6:00 PM did not have an effect (Appendix Table 2).

Our analysis suggested that the PHSMs were critical for suppressing the third and fourth waves of COVID-19 in Hong Kong. However, we found that a ban on dine-in hours after 6:00 PM might not have had an effect in both waves when capacity was already reduced. A complete closure of restaurants in Hong Kong would have considerable social impact because dining out is very common. We 
hypothesize that encouraging restaurants to extend dine-in hours, but with capacity restrictions to reduce crowding, could be a reasonable approach to reduce transmission.

A limitation of our analysis is that we cannot distinguish the effect of some PHSMs because they began simultaneously. We cannot rule out that a ban on dine-in service after 6:00 PM might have an effect if it began earlier than other PHSMs or in regions with high incidences. In addition, changes in $R_{t}$ are a consequence of individual behavioral changes such as avoiding crowded areas; increasing incidence and implementation of multiple PHSMs could raise the public's perception of risk. Determining the effectiveness of alternative PHSMs would provide evidencebased guidance on control strategies.

This project was supported by the Health and Medical Research Fund, Food and Health Bureau, Government of the Hong Kong Special Administrative Region (grant no. COVID190118) and the Collaborative Research Fund (project no. C7123-20G), and by the general research fund (project no. 17110221) of the Research Grants Council of the Hong Kong SAR Government. B.J.C. and P.W. are supported by the AIR@innoHK program of the Innovation and Technology Commission of the Hong Kong SAR Government.

\section{About the Author}

Ms. Ho is a research postgraduate student at the School of Public Health, University of Hong Kong. Her research interest is the transmission and control of emerging infections.

\section{References}

1. The Centre for Health Protection (CHP) of the Department of Health (DH) of Hong Kong. CHP investigates 13 additional confirmed cases of COVID-19. 2021 [cited 2021 Apr 15]. https:/ / www.info.gov.hk/gia/general/202104/13/ P2021041300746.htm

2. The Government of the Hong Kong Special Administrative Region. Government further tightens social distancing measures. 2020 [cited 2021 Mar 29]. https:/ / www.info.gov.hk/ gia/general/202007/14/P2020071400010.htm

3. Lu J, Gu J, Li K, Xu C, Su W, Lai Z, et al. COVID-19 outbreak associated with air conditioning in restaurant, Guangzhou, China, 2020. Emerg Infect Dis. 2020;26:1628-31. https://doi.org/10.3201/eid2607.200764

4. Flaxman S, Mishra S, Gandy A, Unwin HJT, Mellan TA, Coupland H, et al.; Imperial College COVID-19 Response Team. Estimating the effects of non-pharmaceutical interventions on COVID-19 in Europe. Nature. 2020;584:25761. https:// doi.org/10.1038/s41586-020-2405-7

5. Islam N, Sharp SJ, Chowell G, Shabnam S, Kawachi I, Lacey B, et al. Physical distancing interventions and incidence of coronavirus disease 2019: natural experiment in
149 countries. BMJ. 2020;370:m2743. https:// doi.org/ 10.1136/bmj.m2743

6. Brauner JM, Mindermann S, Sharma M, Johnston D, Salvatier J, Gavenciak T, et al.; Inferring the effectiveness of government interventions against COVID-19. Science. 2021;371:6531

7. The Government of the Hong Kong Special Administrative Region. Press releases. 2020 [cited 2021 Mar 21]. https:// www.info.gov.hk/gia/general/today.htm

8. Cori A, Ferguson NM, Fraser C, Cauchemez S. A new framework and software to estimate time-varying reproduction numbers during epidemics. Am J Epidemiol. 2013;178:1505-12. https://doi.org/10.1093/aje/kwt133

9. Tsang T, Wu P, Lau E, Cowling BJ. Accounting for imported cases in estimating the time-varying reproductive number of coronavirus disease 2019 in Hong Kong. J Infect Dis. 2021;224:783-87. https://doi.org/10.1093/infdis/jiab299

10. Friedman J, Hastie T, Tibshirani R. Regularization paths for generalized linear models via coordinate descent. J Stat Softw. 2010;33:1-22. https://doi.org/10.18637/ jss.v033.i01

Address for correspondence: Tim K. Tsang, University of Hong Kong - WHO Collaborating Centre for Infectious Disease Epidemiology and Control, School of Public Health, Li Ka Shing Faculty of Medicine, Patrick Manson Building, 7 Sassoon Rd, Pokfulam, Hong Kong School of Public Health, Hong Kong; email: timtsang@connect.hku.hk

\section{Subcutaneous Nodules Caused by Tropheryma whipplei Infection}

\author{
Lili Wang, Peng Su, Li Song, Lintao Sai \\ Author affiliation: Shandong University Qilu Hospital, Shandong, \\ China
}

DOI: https://doi.org/10.3201/eid2803.211989

To help clarify the clinical manifestations, diagnosis, and treatment for Whipple disease, we report a case of a man in China infected with Tropheryma whipplei. The patient had multiple subcutaneous nodules as the only manifestation, which was not consistent with the typical symptoms of $T$. whipplei infection.

W hipple disease was reported in 1907 and is a chronic infectious disease caused by the bacterium Tropheryma whipplei (1). This disease can involve 